\title{
SERIES REPRESENTATIONS OF THE REMAINDERS IN THE EXPANSIONS FOR CERTAIN TRIGONOMETRIC FUNCTIONS AND SOME RELATED INEQUALITIES, I
}

\author{
ChaO-Ping Chen And Richard B. PARis
}

\begin{abstract}
We present series representations of the remainders in the expansions for certain trigonometric and hyperbolic functions. From these results, we establish some inequalities for trigonometric and hyperbolic functions.
\end{abstract}

Mathematics subject classification (2010): 11B68, 26D05.

Keywords and phrases: Bernoulli numbers, Euler numbers, trigonometric function, hyperbolic function, inequalities.

\section{REFERENCES}

[1] M. Abramowitz And I. A. Stegun (eds.), Handbook of Mathematical Functions with Formulas, Graphs, and Mathematical Tables, National Bureau of Standards, Applied Mathematics Series 55, 9th printing, Washington, 1970.

[2] B. BAnjaC, M. MAKRAGiĆ And B. MALEŠEviĆ, Some notes on a method for proving inequalities by computer, Results. Math. 69, 1 (2016), 161-176.

[3] M. Becker And E. L. STRAK, On a hierarchy of quolynomial inequalities for $\tan x$, Univ. Beograd. Publ. Elektrotehn. Fak. Ser. Mat. Fiz. No. 602-633 (1978), 133-138.

[4] C.-P. Chen And W.-S. Cheung, Sharp Cusa and Becker-Stark inequalities, J. Inequal. Appl. 2011 (2011), 136, http://www.journalof inequalitiesandapplications.com/content/ $2011 / 1 / 136$.

[5] C.-P. CHEN AND R. B. PARIS, Series representations of the remainders in the expansions for certain functions with applications, Results. Math. 2016, DOI: 10.1007/s00025-016-0612-1.

[6] C.-P. Chen AND F. QI, A double inequality for remainder of power series of tangent function, Tamkang J. Math. 34, 4 (2003), 351-355.

[7] C.-P. CHEN AND J. SÁNDOR, Sharp inequalities for trigonometric and hyperbolic functions, J. Math. Inequal. 9, 1 (2015), 203-217.

[8] L. Debnath, C. Mortici And L. Zhu, Refinements of Jordan-Stečkin and Becker-Stark inequalities, Results Math. 67 (2015), 207-215.

[9] H.-F. GE, New sharp bounds for the Bernoulli numbers and refinement of Becker-Stark inequalities, J. Appl. Math. 2012, Article ID 137507, 7 pages.

[10] I. S. GRADSHTEYN AND I. M. RYZHIK, Table of integrals, series, and products, translated from the Russian, Sixth edition, translation edited and with a preface by Alan Jeffrey and Daniel Zwillinger, Academic Press, Inc., San Diego, CA, 2000.

[11] S. Koumandos, On completely monotonic and related functions, Mathematics Without Boundaries, pp. 285-321. Springer, New York, 2014.

[12] Y. NishizAWA, Sharp Becker-Stark's type inequalities with power exponential functions, J. Inequal. Appl. 2015 (2015) 402, http://rd.springer.com/article/10.1186/s13660-015-0932-9/ fulltext.html.

[13] F. W. J. Olver, D. W. Lozier, R. F. Boisvert, C. W. Clarks (eds.), NIST Handbook of Mathematical Functions, Cambridge University Press, New York, 2010. 
[14] Z.-J. SUN AND L. ZHU, Simple proofs of the Cusa-Huygens-type and Becker-Stark-type inequalities, J. Math. Inequal. 7 (2013), 563-567.

[15] J.-L. ZHAO, Q.-M. LuO, B.-N. GuO AND F. QI, Remarks on inequalities for the tangent function, Hacet. J. Math. Stat. 41, 4 (2012), 499-506.

[16] L. ZHU, Sharp Becker-Stark-type inequalities for Bessel functions, J. Inequal. Appl. 2010, Article ID 838740,4 pages.

[17] L. ZHU, A refinement of the Becker-Stark inequalities, Math. Notes 93 (2013), 421-425.

[18] L. ZhU AND J. K. HUA, Sharpening the Becker-Stark inequalities, J. Inequal. Appl. 2010, Article ID 931275, 4 pages. 